* Mestre em Direito Negocial e Especialista em Direito Empresarial pela Universidade Estadual de Londrina (UEL-PR). E-mail: juliana hinterlang@gmail.com

** Professora da graduação e do programa de mestrado na Universidade Estadual de Londrina. Doutora em Direito pela Pontifícia Universidade Católica de São Paulo. E-mail: mkempferb @gmail.com

\section{Interpretação sistêmica e a possibilidade de recuperação judicial para as sociedades em comum}

\author{
SYSTEMIC INTERPRETATION AND THE POSSIBILITY OF \\ JUDICIAL RECOVERY FOR SOCIETIES IN COMMON \\ * Juliana Hinterlang dos Santos Costa \\ ** Marlene Kempfer
}

Resumo: A Sociedade em Comum foi introduzida na legislação brasileira a partir do Código Civil de 2002 em seus artigos 986 a 990. Em período anterior ela era analisada sob a denominação sociedade irregular ou sociedade de fato. A primeira se caracterizava por haver contrato escrito, mas, este não havia sido levado a registro perante o órgão competente e a segunda quando não havia o contrato social. Este estudo tem por objetivo analisar a figura da Sociedade em Comum, no atual ordenamento jurídico, a partir da interpretação majoritária que não reconhece o direito à recuperação judicial. Aponta-se que esta interpretação desconsidera: i) princípios que regem a ordem jurídica e o subsistema econômico; e, ii) que a legislação atual permite a sua responsabilização diante de deveres jurídicos nas esferas trabalhista, tributária, concorrencial e consumerista. Sob estes principais argumentos é que têm destaque a interpretação sistemática para defender o direito à recuperação judicial. Assim, efetiva-se a segurança jurídica material.

Palavras-Chave: Análise sistêmica; Recuperação de empresa; Sociedade em comum.

Abstract: The Society in Common was introduced in the Brazilian legislation in articles 986 to 990 of the Civil Code of 2002. In period before it, was analyzed like irregular society or company in fact. The first was characterized by having written contract, but this had not been brought to registration with the competent body and the second when there was not the social contract. This study aims to analyze the figure of the Society in Common, in the current legal system, from the majority interpretation, that does not recognize the right to judicial recovery. It is pointed out that this interpretation ignores: i) the principles of the legal system and of the economic subsystem; and, ii) that the current legislation allows their accountability before legal duties in labor spheres, tax, competitive and consumerist. In these main arguments, that is highlighted the systematic interpretation to defend the right to judicial recovery. So the material legal security is effective.

Keywords: Systemic analysis; Recovery company; Society in common. 


\section{INTRODUÇÃO}

A Sociedade em Comum foi instituída no ordenamento jurídico brasileiro a partir do Código Civil de 2002 entre as denominadas sociedades despersonificadas, para unificação das antigas sociedades de fato e irregulares. Prevê o art. 986 que as Sociedades em Comum são aquelas que não levaram seus atos constitutivos a registro perante a Junta Comercial e, por isso, são consideradas informais.

Vale destacar alguns dados interessantes sobre as Sociedades em Comum no cenário econômico brasileiro. Olivon (2013) em reportagem produzida para a revista Exame trouxe informações sobre o quanto do Produto Interno Bruto (PIB) do Brasil foi produzido através das atividades informais: "A chamada economia subterrânea (produção de bens e serviços não reportada ao governo, que fica à margem do PIB nacional) chegou a 730 bilhões de reais em 2012", sendo que esse montante "representava no final de 2012 o equivalente a 16,6 \% do PIB", essas informações foram retiradas do Índice de Economia Subterrânea (IES) elaborado pelo Instituto Brasileiro de Ética Concorrencial (ETCO) com o IBRE/FGV.

Quanto ao número de trabalhadores abarcados pelo mercado informal, o Instituto Brasileiro de Geografia e Estatísticas (2014), na Síntese de Indicadores Sociais, estimou no ano de 2014 que o Brasil contava com "40 milhões de pessoas ocupadas em trabalhos informais"

Mesmo tendo considerável participação na geração de empregos e renda no Brasil, atualmente, a Sociedade em Comum fica impossibilitada de usufruir o direito à recuperação judicial, por não ter levado seus atos constitutivos a registro. Qualifica-se esta interpretação de injusta, uma vez que diante das obrigações legais nas esferas trabalhista, consumerista, tributária, consumidor e concorrencial, ela é chamada a responder por seus atos.

O presente estudo tem por escopo fazer uma análise sistêmica do ordenamento pátrio, para viabilizar a recuperação judicial das Sociedades em Comum, sem que isso gere insegurança jurídica. Ao contrário, destaca-se, a importância de mantê-la no mercado, nas hipóteses em que sejam viáveis economicamente, pois trarão benefícios para o domínio econômico.

Em pesquisa realizada pela Confederação Nacional dos Dirigentes Lojistas - CNDL e pelo Serviço de Proteção ao Crédito SPC/Brasil, verificou- 
se que as atividades tidas como informais, como é o caso das Sociedades em Comum, vislumbram "o crescimento dos seus negócios dado que $82 \%$ deles disseram tentar sempre melhorar seu negócio e que $75 \%$ pensam em ampliá10” (CONFEDERAÇÃO NACIONAL DOS DIRIGENTES LOGISTAS, 2013, p. 4). A possibilidade de recuperação para as Sociedades em Comum vem de encontro com esse desejo dos empreendedores, já que poderiam de fato ampliar seu negócio e com isso contribuir para a geração de emprego, receitas tributárias e com o ambiente concorrencial como um todo.

Para o desenvolvimento deste trabalho, utilizou-se do método dedutivo, analisando as legislações pertinentes ao tema, para aplicá-las ao caso da recuperação judicial das Sociedades em Comum.

\section{A RESPONSABILIZAÇÃO DOS SÓCIOS PERANTE AS DÍVIDAS DAS SOCIEDADES EM COMUM}

O Código Civil de 2002, utilizando-se da expressão já trazida no Código Comercial de 1850, optou por denominar as sociedades que não possuem seus atos constitutivos registrados no órgão competente de Sociedades em Comum. Não se trata, portanto, de nova espécie societária, mas apenas de nova denominação, conforme enunciado $n^{\circ} 58$ da Jornada de Direito Civil "art. 986 e seguintes: a Sociedade em Comum compreende as figuras doutrinárias da sociedade de fato e da irregular" (BRASIL. 2002).

Fiuzza (2004, p. 909) ao comentar sobre o art. 986 do Código Civil (CC), traz conceito de Sociedade em Comum:

A Sociedade em Comum é um tipo de sociedade não personificada, cons-tituída de fato por sócios para o exercício de atividade empresarial ou produtiva, com repartição de resultados, mas cujo ato constitutivo não foi levado para inscrição ou arquivamento perante o registro competente.

No atual regramento, as Sociedades em Comum abrangem as sociedades que no mundo fático reúnem os requisitos de atividade econômica, além daquelas que possuem contrato escrito, mas que ainda não realizaram o registro de seus atos constitutivos junto ao órgão competente, que no Brasil são as Juntas Comerciais ou Registro Público de Empresas Mercantis.

Essas sociedades normalmente dispõem de faturamento baixo e podem ser enquadradas entre as microempresas, empresas de pequeno porte ou 
empreendimentos econômicos solidários.

As Sociedades em Comum estão previstas no Código Civil de 2002 nos arts. 986 a 990, utilizando-se, subsidiariamente, as normas congruentes e compatíveis das Sociedades Simples estabelecidas pelos arts. 997 a 1000 para sua regulamentação.

Impõe o texto do Código Civil que é imprescindível o arquivamento do contrato social no registro próprio e que, enquanto não o fizer, a sociedade deixa de adquirir personalidade jurídica própria, conforme previsto em seu art. 45, "começa a existência legal das pessoas jurídicas de direito privado com a inscrição do ato constitutivo no respectivo registro, precedida, quando necessário, de autorização ou aprovação do Poder Executivo [...]" (BRASIL, 2002).

A principal discussão existente nesse quesito diz respeito ao termo empregado para configurar essa espécie societária. Estaríamos diante de uma atividade empresária irregular ou apenas informal?

Martins (1998, p. 237) posiciona-se no sentido de que a sociedade será irregular, quando:

[...] se organiza legalmente, arquiva seus atos constitutivos no Registro do Comércio mas, posteriormente, pratica atos que desnaturam o tipo social (por exemplo: uma sociedade em comandita simples por prazo determinado ultrapassa esse prazo sem renovar o contrato social; continua a sociedade a funcionar irregularmente, perdendo, os sócios comanditários, esse benefício, tornando-se ilimitadamente responsáveis); ou que funciona sem cumprir as obrigações impostas por lei (não possui livros obrigatórios, não levanta o balanço anual).

A Sociedade em Comum, ao ser constituída visando a exploração de atividade empresarial lícita, não pode ser considerada irregular, mas informal, por não preencher uma forma estabelecida em lei, que é o registro do contrato social. Somente seria considerada irregular se os seus sócios praticassem atos que pudessem comprometer a espécie societária escolhida, por exemplo, a exploração de objeto ilícito.

Corrobora com esse entendimento Lanza Neto (2008, p. 6777) para quem a regularidade da Sociedade em Comum relaciona-se com os atos praticados por ela em consonância com a legislação e não a forma pela qual veio a ser constituída: 
A irregularidade da Sociedade em Comum não é verificada pela ausência de arquivamento de eventual Contrato Social junto ao Registro Público de Empresas Mercantis (art. 985 do CC) ou mediante contrato escrito, particular ou público devidamente inscrito no Registro Civil das Pessoas Jurídicas (no caso da Sociedade Simples - artigos 997 e 998 do CC). [...] Ou seja, sendo as atividades empresariais da Sociedade em Comum desenvolvidas em conformidade com a lei, é considerada como regular.

A Sociedade em Comum, tendo seu objeto de exploração lícito, mantendo anotações contábeis de suas atividades, de acordo com a solicitação legal, não pode ser considerada irregular, mas apenas informal, posto que sua atividade está ligada ao desenvolvimento do mercado.

O Código Civil ainda estabelece a existência de um patrimônio separado, afeto à atividade empresária. Em seu art. 988, estatui que "os bens e dívidas sociais constituem patrimônio especial, do qual os sócios são titulares em comum" (BRASIL, 2002).

A demonstração legal da existência de um patrimônio, separado para a própria atividade, expõe o seu caráter societário. Este é um dos atributos decorrentes de personalização. Gonçalves Neto (2008, p. 141) assevera que "se a sociedade não se registra para atuar regularmente, mas, ainda assim, desenvolve atividade econômica, os atributos da personalidade não lhe podem ser franqueados". Esse patrimônio não pertence a um dos sócios, ou a cada um de forma individualizada, ao contrário, o patrimônio é destacado do patrimônio dos sócios, constituindo-se um novo patrimônio que será utilizado para o desenvolvimento da atividade, além de ser acrescido dos resultados dali obtidos. O escopo desse patrimônio afeto à atividade é garantir o pagamento das dívidas contraídas pela Sociedade em Comum perante os credores, mais um motivo pelo qual a recuperação judicial não deve ser negada.

Entre as previsões do Código Civil, a que se mostra mais importante para esse estudo está ligada a responsabilidade dos sócios perante as dívidas sociais e ao benefício de ordem, pois conforme estabelece o art. 990 "todos os sócios respondem solidária e ilimitadamente pelas obrigações sociais, excluído do benefício de ordem, previsto no art. 1.024, aquele que contratou pela sociedade" (BRASIL, 2002).

A principal novidade em relação à Sociedade em Comum está na previsão do art. 990, que estabelece que os sócios somente respondem com seus bens pessoais, após esgotado todo o patrimônio especial, separado para 
a atividade. Todavia, aquele que contratou pela Sociedade está excluído desse benefício de ordem, que é aquele previsto no art. 1.024 do Código Civil "os bens particulares do sócio não podem ser executados por dívidas das sociedades, senão depois de executados os bens sociais" (BRASIL, 2002).

A responsabilidade dos sócios da Sociedade em Comum vem a ser subsidiária, ou seja, primeiro o patrimônio afeto e, em seguida, o patrimônio pessoal. Enquanto o administrador, ou seja, aquele que contratou em nome da Sociedade, tem responsabilidade solidária pelo cumprimento das obrigações contratuais. Isso implica que, em não havendo cumprimento das cláusulas do contrato, o terceiro que com a sociedade contratou poderá exigir o seu cumprimento seja do sócio ou da sociedade, de forma indistinta.

No Código Civil, fica claro que a natureza jurídica da Sociedade em Comum é de sociedade empresária desde que ela exerça atividades típicas de empresário e não aquelas excluídas pelo art. 966, parágrafo único, profissão intelectual, de natureza científica, literária ou artística. Quanto à aquisição de personalidade jurídica pelo registro, a discussão se dará em momento oportuno.

\section{RESPONSABILIDADE DA SOCIEDADE EM COMUM NO ORDENAMENTO JURÍDICO BRASILEIRO}

Como observado anteriormente, os sócios das Sociedades em Comum são os responsáveis pelas dívidas da sociedade, depois de esgotado o patrimônio especial. Este capítulo pretende analisar a possibilidade de responsabilidade da Sociedade em Comum e dos seus sócios, perante a legislação concorrencial, tributária, trabalhista e consumerista, para viabilizar a recuperação judicial da Sociedade em Comum, tendo os sócios como responsáveis subsidiários.

\subsection{A Sociedade em Comum Frente a Lei de Concorrência}

O Sistema Brasileiro de Defesa da Concorrência, instituído pela lei 12.529/2011 (BRASIL, 2011), é o responsável pela repressão ao abuso do poder econômico que tenha por escopo a dominação dos mercados, a eliminação da concorrência, além aumento arbitrário dos lucros, de acordo com a previsão do art. $173, \S 4^{\circ}$ da Constituição Federal e prevenção que vise evitar práticas anticompetitivas.

A Lei de Defesa da Concorrência, quanto ao aspecto repressivo, estabelece a responsabilidade civil e administrativa das pessoas jurídicas, além 
dos entes despersonalizados que venham a praticar ilícitos contra a ordem econômica e a economia popular, nos termos do art. $173, \S 5^{\circ}$ da Constituição Federal:

$\S 5^{\circ}$ - A lei, sem prejuízo da responsabilidade individual dos dirigentes da pessoa jurídica, estabelecerá a responsabilidade desta, sujeitando-a às punições compatíveis com sua natureza, nos atos praticados contra a ordem econômica e financeira e contra a economia popular (BRASIL, 1988).

Dispõe este texto legal que os entes despersonalizados, podem e serão responsabilizados perante os ilícitos concorrenciais, uma vez que a lei estabelece uma ampla legitimação passiva e prevê uma abrangente possibilidade de responsabilização dos agentes econômicos por condutas anticoncorrenciais, conforme art. 31, retro:

Esta Lei aplica-se às pessoas físicas ou jurídicas de direito público ou privado, bem como a quaisquer associações de entidades ou pessoas, constituídas de fato ou de direito, ainda que temporariamente, com ou sem personalidade jurídica, mesmo que exerçam atividade sob regime de monopólio legal (BRASIL, 2011).

Nesse mesmo sentido, o art. 32 da Lei 12.529/2011 estabelece que "As diversas formas de infração da ordem econômica implicam a responsabilidade da empresa e a responsabilidade individual de seus dirigentes ou administradores, solidariamente" (BRASIL, 2011).

No que tange ao aspecto repressivo, de atuação dos órgãos do Sistema Brasileiro de Defesa da Concorrência, não existe na jurisprudência do CADE decisão que tenha por sujeito ativo da infração uma Sociedade em Comum, ou ente despersonalizado ${ }^{1}$, isto porque para infringir uma norma da concorrência, o infrator deve possuir poder econômico, conforme o entendimento pacífico do CADE, abaixo colacionado:

Não pode infringir a ordem econômica quem não disponha de poder econômico capaz de, por seu abuso, restringir ou limitar a livre concorrência no mercado relevante (Averiguação Preliminar nº 080000.011085/94-62 Conselheiro Artur Barrionuevo Filho).

\footnotetext{
Quando utilizado para pesquisa os termos "ente despersonalizado", "despersonalizado", "Sociedade em Comum", "Sociedade de Fato", "Sociedade Irregular" não houve resposta positiva no site do CADE http://www.cade.gov.br/Default.aspx?e15cb044c84cdd37c95ea276bc56d673c6.
} 
EMPRESA DE PEQUENO PORTE. INEXISTÊNCIA DE INFRAÇÃO À ORDEM ECONÔMICA. A presença de poder de mercado é indispensável ao reconhecimento do abuso (Averiguação Preliminar nº 08000.016012/9476 - Conselheiro Artur Barrionuevo Filho).

A infração à ordem exige que o sujeito ativo da infração detenha poder de mercado (Representação n ${ }^{\circ}$ 87/92, Conselheiro Leônidas Xausa (CENTRO ADMINISTRATIVO DE DEFESA ECONÔMICA, 2007, p. 15).

Quanto ao aspecto de atuação preventiva, tem-se que a competição entre os agentes econômicos nem sempre é livre e perfeita, dependendo, principalmente, da natureza dos mercados e das políticas econômicas. Querse com esta intervenção, evitar os comportamentos monopolistas, pois quanto maior é o poder de mercado de um agente econômico, maior é a chance de ele se comportar de maneira a reduzir as ofertas e aumentar os preços.

Segundo Centro Administrativo de Defesa Econômica - CADE (2007, p. 18) seu papel preventivo "corresponde basicamente à análise das alterações estruturais do mercado, apresentadas sob a forma dos atos de concentração ou qualquer outra forma que possa afetar negativamente a concorrência”.

O CADE deverá analisar economicamente cada caso em concreto, para que, havendo dominação de mercado, ainda que realizado por Sociedades em Comum, ele possa buscar evitar a concentração empresarial que seja prejudicial ao mercado concorrencial e aos consumidores.

O Regime Jurídico da Capacidade Tributária e a Obrigação de Pagar Tributos Pelas Sociedades em Comum

Para entender a capacidade tributária das Sociedades em Comum e a sua obrigação de pagar tributos, necessário que se faça a utilização de um enfoque sistêmico, abordando a questão na esfera doutrinária e jurisprudencial, na seara Constitucional, para, em seguida, analisar o Código Tributário Nacional (CTN).

A Constituição Brasileira de 1988 prevê o dever fundamental de pagar tributos em seu art. 145 ao estabelecer aos entes federados competências para instituir tributos, criados por leis que determinam quem são os respectivos contribuintes. O dever de pagar tributos está relacionado aos meios pelos quais o Estado realiza os objetivos com os quais se comprometeu, revelando sua soberania.

Este dever fundamental deve ser interpretado de duas maneiras, a primeira em relação à obrigatoriedade de instituir os tributos previstos na 
Constituição, por parte dos entes federados, já que os tributos são a principal fonte de recursos para concretização das políticas públicas e responsabilidades estatais; e a segunda, que é a mais importante nesse estudo, está relacionada ao aspecto de que todos estão sujeitos às incidências tributárias, na medida de suas capacidades contributivas individuais, conforme previstas na Constituição, no Código Tributário Nacional com normas gerais, e nas legislações tributárias nas esferas federal, estadual e municipal. Razão pela qual devem cumprir com a obrigação tributária. Tal conclusão decorre da própria ordem constitucional e dos objetivos que a fundamentam.

Diante da obrigação imposta pela Constituição, de que todos devem pagar tributos, na medida de suas capacidades, é importante analisar a relação jurídico-tributária, em seu critério pessoal, mais especificamente na figura do contribuinte diante da capacidade tributária passiva, no intuito de entender a responsabilidade tributária das Sociedades em Comum.

A ocorrência do evento tributário, no plano fático, além da subsunção do fato à hipótese tributária é o que importa para fins de tributação, criando direitos e deveres na relação jurídica, a partir de onde se analisa a capacidade tributária passiva.

A capacidade tributária passiva independe da capacidade civil, de existir medidas que importem privação ou limitação do exercício de atividades civis, comerciais ou profissionais para as pessoas naturais. Paulsen (2012, p. 113) conclui "que quem realiza o fato gerador está obrigado ao pagamento do tributo, ainda que não tenha ou não esteja no gozo de capacidade civil plena ou que esteja atuando mediante sociedade irregular ou de fato". Para as pessoas jurídicas, não existe necessidade de regularização, nos termos do Código Civil, basta a configuração de uma unidade econômica ou profissional, de acordo com o disposto no art. 126 do Código Tributário Nacional.

Concorda com esse posicionamento Amaro (2007, p. 330) "a sociedade de fato ou a sociedade irregular também não são circunstâncias impeditivas do nascimento de obrigações tributárias, surgidas pela ocorrência de fatos geradores identificáveis no exercício das atividades dessas sociedades"

Ainda nesse sentido, importante o entendimento trazido pelo Tribunal Regional Federal da $4^{\mathrm{a}}$ Região ao analisar a Apelação/Reexame Necessário $\mathrm{n}^{\circ}$ 2003.70.02.003303-8 em que o contribuinte de Imposto de Renda de Pessoa Física (IRPF) realizava atividade de revenda de carro, sem contudo contar com o registro, abaixo: 
IMPOSTO DE RENDA PESSOA FÍSICA. NULIDADE DE PROCEDIMENTO FISCAL. OMISSÃO DE RENDIMENTOS. ACRÉSCIMO PATRIMONIAL À DESCOBERTO. REVENDA DE VEÍCULOS. HONORÁRIOS. SUCUMBÊNCIA RECÍPROCA. O artigo 126, inciso III, do Código Tributário Nacional prevê que a capacidade tributária passiva independe de estar a pessoa jurídica regularmente constituída, bastando que configure uma unidade econômica ou profissional. [...] Embora o autor não tenha apresentado documentação hábil a comprovar ser proprietário de revenda de veículos, os negócios por ele efetuados levam à conclusão de que os adquiria com a finalidade de comercializá-los. Em conformidade o princípio da interpretação objetiva do fato gerador, é irrelevante a regularidade da atividade desenvolvida pelo contribuinte para que o Fisco, verificando a existência de omissão fiscal, efetue o lançamento, independentemente de o contribuinte ter registrado ou não seus atos constitutivos na junta comercial (BRASIL, 2008).

O contribuinte, mesmo não comprovando sua condição de pessoa jurídica, foi tributado no Imposto de Renda de Pessoa Jurídica (IRPJ), pois houve omissão fiscal, já que o fato jurídico relevante para a tributação ocorreu, qual seja, a revenda de veículos, independente de seus atos constitutivos estarem ou não arquivados na Junta Comercial. Entendeu-se pela aplicação da Instrução Normativa Secretaria da Receita Federal - SRF n ${ }^{0} 152 / 1998$, que trata da base de cálculo das operações de venda de veículos usados, adquiridos para revenda, o que levou ao lançamento de ofício pelo Fisco em razão da omissão físcal.

Reconhecido está que a Sociedade em Comum realiza eventos passíveis de serem considerados fatos jurídicos relevantes para a tributação. Importante, nesse momento, analisar a hipótese do não pagamento do tributo pela Sociedade em Comum e a possibilidade de Execução Fiscal para o seu recebimento.

Para isso, é importante analisar a inscrição em dívida ativa apenas no aspecto que é de interesse para esta pesquisa, quanto a emissão da Certidão de Dívida Ativa (CDA). Por meio de processo administrativo de dívida ativa, a Fazenda Pública torna o crédito tributário passível de execução. Bartini (2012, p. 168) assevera que: “A inscrição em dívida ativa somente poderá ocorrer quando o crédito tributário devidamente constituído não foi pago no vencimento". E continua "Tal inscrição será realizada pela autoridade competente para que se possa cobrar judicialmente o crédito tributário que não fora quitado no prazo, com os devidos encargos legais". O crédito tributário 
deve estar regularmente constituído e o prazo para pagamento deve ter sido encerrado para que a inscrição em dívida ativa possa ocorrer.

No caso da Sociedade em Comum, que não possui personalidade jurídica conferida por lei, prevê Carvalho (2009, p. 346-347) que se o legislador "pretende inscrever, na hipótese normativa, sujeito sem personalidade jurídica, outorgando-lhe capacidade para realizar o acontecimento tributário" deverá prescrever a pessoa física ou jurídica admitidas por lei no intuito de responsabilizar-se pelo ente que promoveu o evento.

Isso significa que, seguindo os parâmetros do Código Civil, em seu art. 990 caberia aos sócios da Sociedade em Comum responderem pela dívida tributária, na modalidade de responsável tributário, sendo que a responsabilidade entre eles é solidária e ilimitada.

A solidariedade passiva tributária é determinada pelo que prevê o art. 124 do CTN, verbis:

Art. 124. São solidariamente obrigadas:

I - as pessoas que tenham interesse comum na situação que constitua o fato gerador da obrigação principal;

II - as pessoas expressamente designadas por lei.

Parágrafo único. A solidariedade referida neste artigo não comporta benefício de ordem (BRASIL, 1966).

$\mathrm{Na}$ hipótese dos sócios da Sociedade em Comum, a solidariedade decorre do interesse em que possuem na situação que constituiu o fato jurídico tributário da obrigação, ou seja, a responsabilidade será assumida pelos sócios em razão da confusão patrimonial.

No âmbito tributário, há o reconhecimento da Sociedade em Comum entre os sujeitos de fato da relação jurídico tributária, detentora de capacidade passiva tributária, enquanto a capacidade de direito, fica adstrita aos seus sócios a responsabilidade pelas obrigações tributárias contraídas, inclusive quanto aos deveres instrumentais.

\subsection{O Código de Defesa Do Consumidor e a Responsabilização das Sociedades em Comum}

O Código de Defesa do Consumidor (CDC) também prevê a possibilidade de responsabilização dos entes despersonalizados na figura do fornecedor diante de uma relação de consumo. Em seu art. $3^{\circ}$ considera 
fornecedor "toda pessoa física ou jurídica, pública ou privada, nacional ou estrangeira, bem como os entes despersonalizados" (BRASIL, 1990).

Filomeno (2007, p. 35) entende que fornecedores são "todos quanto propiciem a oferta de produtos e serviços no mercado de consumo, de maneira a atender as necessidades dos consumidores, sendo despiciendo indagar-se a que título". Para o autor, não importa se a oferta é a título gratuito ou oneroso, basta que haja a relação de entrega do produto ou serviço.

No intuito de entender o real conceito de fornecedor, para então analisar a responsabilização das Sociedades em Comum, é necessário um maior aprofundamento e desenvolvimento no conceito estabelecido pela legislação consumerista.

$\mathrm{O}$ art. $3^{\circ}$ não trata da necessidade de habitualidade e profissionalismo para que o ente possa ser responsabilizado perante o CDC. Lisboa (2001, p. 112) é um dos autores que discorda e assevera que "Fornecedor é toda pessoa física ou jurídica que, no exercício de sua atividade profissional econômica, lança produtos ou serviços no mercado de consumo". Para o autor há necessidade do quesito profissionalidade para a configuração do fornecedor.

Não é possível concordar com a necessidade de profissionalismo para o enquadramento no quesito fornecedor. A análise deve partir do pressuposto de que o fornecimento visou a participação no mercado de consumo, de modo a suprir as necessidades do consumidor, ainda que não seja de forma profissional. Exemplo clássico é o apresentado por Andrade (2006, p. 30) onde um engenheiro, que tem por profissão a engenharia, porém, também atua vendendo perfumes. Nesse caso, o profissionalismo dele está relacionado à engenharia, todavia, não é porque ele vende perfumaria apenas para incremento na renda, ou seja, de forma não profissional, que não poderá ser responsabilizado por algum vício apresentado.

No que diz respeito ao profissionalismo, interessante exemplo é trazido por Nunes $(2012$, p. 122) ao abordar a figura do consumidor. Se a pessoa adquire peças de vestuário para revendê-las, ele deixa de ser consumidor, e passa a ser fornecedor, mesmo que não o faça de forma profissional.

Outro requisito que não é essencial para a configuração do fornecedor é a habitualidade, já que diversas atividades ocorrem apenas em determinados períodos durante o ano, ou apenas dias. Nunes (2012, p. 135) entende pela desnecessidade de trabalho habitual, citando o exemplo de uma estudante que revende lingeries aos seus colegas para pagar os estudos. Mesmo que essa revenda ocorresse apenas no período natalino ou de férias, ela seria 
considerada fornecedora pois sua atividade apesar de eventual é comercial e passível de responsabilização nos termos do CDC.

O descumprimento de obrigações impostas pelo regime consumerista impõe aos fornecedores sanções, independentemente de estarem regularmente constituídas nos termos da lei civil. Ou seja, sua condição jurídica não é óbice para que lhe sejam imputadas obrigações em relação aos consumidores de seus produtos ou serviços.

Depois dessa exposição acerca dos requisitos para a configuração do fornecedor, conforme art. $3^{\circ}$ do CDC, é importante fazer um retorno ao início dessa discussão, quando se afirmou sobre a possibilidade dos entes despersonalizados serem considerados fornecedores, situação que possibilitaria a responsabilização das Sociedades em Comum por vícios em seus produtos ou serviços.

Os entes despersonalizados, citados no CDC são, nas palavras de Filomeno (2007, p. 47-48) "os que embora não dotados de personalidade jurídica, quer no âmbito mercantil, quer no civil, exercem atividades produtivas de bens e serviços". É o caso da Sociedade em Comum, segundo o que dispõe o Código Civil.

No Recurso Especial n ${ }^{\circ}$ 519.310/SP, a relatora Ministra Nancy Andrighi entendeu que:

Para o fim de aplicação do Código de Defesa do Consumidor, o reconhecimento de uma pessoa física ou jurídica ou de um ente despersonalizado como fornecedor de serviços atende aos critérios puramente objetivos", hipótese em que considerou "irrelevantes a sua natureza jurídica, a espécie dos serviços que prestam e até mesmo o fato de se tratar de uma sociedade civil, sem fins lucrativos". (REsp 519.310/SP, Rel. Min. NANCY ANDRIGHI, TERCEIRA TURMA) (BRASIL, 2004).

Conforme decidido pela Ministra Nancy Andrighi, a responsabilização de uma atividade empresária perante o consumidor independe de sua natureza jurídica, sendo desnecessária a personalidade jurídica própria para configuração da pessoa jurídica, nos termos do que prevê o Código Civil Brasileiro. Nunes (2012, p. 138) entende que "é de enquadrar no conceito de ente despersonalizado as chamadas pessoas jurídicas de fato: aquelas que, sem constituir uma pessoa jurídica, desenvolvem, de fato, atividade industrial, comercial, de prestação de serviços, etc". 
Nesse sentido, se manifestou Leite (2002, p. 40) para quem "as entidades comerciais ou fabris de fato, isto é, aquelas não constituídas regularmente e popularmente conhecidas como empresas de fundo de quintal, ficam impedidas de utilizar o argumento da falta de personalidade jurídica formal" quando quiserem se evadir de suas responsabilidades para com os consumidores, posto que o CDC as incluiu expressamente quando exercerem atividades produtivas no mercado de consumo.

O Código de Defesa do Consumidor prevê a responsabilização das Sociedades em Comum, pois de forma expressa cita os "entes despersonalizados" entre os fornecedores, já que muitas dessas sociedades existem no ambiente econômico. É neste sentido a afirmação de Nunes (2012, p. 138) "tais sociedades formam um bom número de fornecedores, que suprem de maneira relevante o mercado de consumo". Se elas existem, mais uma vez podem ser responsabilizadas, porém, quanto aos seus direitos, ficam à margem da lei.

\subsection{O Regime Jurídico das Relações de Trabalho e as Sociedades em Comum na Qualidade de Empregadoras}

$\mathrm{Na}$ esfera trabalhista, também é possível a responsabilização da Sociedade em Comum, pois o art. $2^{\circ}$ da Consolidação das Leis do Trabalho (CLT) é extremamente abrangente.

Para o diploma legal acima mencionado, empregador é qualquer "empresa, individual ou coletiva, que, assumindo os riscos da atividade econômica, admite, assalaria e dirige a prestação pessoal de serviço" (BRASIL, 1943).

Os requisitos necessários à configuração do empregado não estão relacionados ao quesito personalidade jurídica da sociedade que o emprega. Basta que o trabalhador preste serviços, de forma subordinada e mediante salário para que seja possível a responsabilização do empregador perante a Justiça do Trabalho, pois os riscos da atividade foram por ele assumidos. Não há lógica para não apreciação dos direitos do trabalhador pelo simples fato de seu empregador não ser uma sociedade empresária legalmente constituída nos moldes do Código Civil. Dubugras (2009, p. 3) assevera que "a empresa empregadora pode ser formal ou informal, liderada por um ou mais indivíduos".

Sendo hipótese de Sociedade em Comum, a responsabilização recairá sobre os sócios de forma solidária, conforme a previsão do Código Civil, 
cabendo a qualquer dos sócios ser responsabilizado por débito decorrente do contrato de trabalho. Esse é o entendimento da jurisprudência brasileira, a $2^{\circ}$

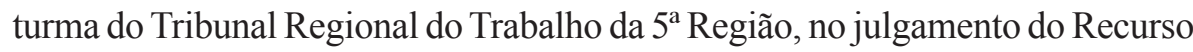
Ordinário n ${ }^{\circ} 36000650055050161$, entendeu pela configuração da sociedade de fato, hoje chamada Sociedade em Comum, onde qualquer dos sócios poderia ser responsabilizado, afastando a preliminar de ilegitimidade passiva arguida por um deles, nos termos abaixo:

Contudo, não há como ser mantida. Isso porque ficou claro tratar-se do que se denomina de sociedade não personificada ou sociedade de fato, representada pela exploração de atividade econômica, sem que estivesse devidamente regularizado o registro dos seus atos constitutivos, sequer existentes. Em tal hipótese, assegura o art. 990, do Código Civil, a responsabilidade solidária e ilimitada dos seus integrantes, o que autoriza o credor a demandar contra qualquer deles, total ou parcialmente, a dívida. Por conseguinte, não há que se falar em ilegitimidade passiva, mormente porque não se caracterizou a sucessão empresarial, na medida em que a própria autora declarou que não mais trabalhou para a mulher do Recorrido, após a separação (BRASIL, 2006).

A Sociedade em Comum, quando explora atividade econômica, possuindo empregados, pode ser responsabilizada por débitos trabalhistas. Afasta-se qualquer tese de que os entes despersonalizados não podem ser considerados empregadores e passíveis de responder judicialmente por infração aos preceitos celetistas. Nesta hipótese, em sendo insuficiente ou na ausência de patrimônio especial, os sócios respondem com bens particulares pelas dívidas trabalhistas, que lhe são transferidas, posto que por não haver constituição legal da atividade empresária, a responsabilidade é ilimitada e solidária entre os sócios.

\section{INTERPRETAÇÃO SISTEMÁTICA E SEGURANÇA JURÍDICA MATERIAL EM DEFESA DA RECUPERAÇÃO JUDICIAL E EXTRAJUDICIAL PARAAS SOCIEDADES EM COMUM}

Para compreender e aplicar o Direito de forma justa é necessário que se adote uma interpretação que considere a totalidade dos valores e normas que integram o do sistema jurídico. 
A interpretação sistemática do Direito visa analisar o conjunto das normas dando-lhes uma extensão maior da realidade que está positivada em termos literais. Segundo Freitas (1995, p. 15):

[...] a interpretação sistemática do Direito tem por objeto o sistema jurídico na sua condição de totalidade axiológica, convindo recordar que, mesmo na tradição romano-germânica, o Direito é maior do que o conjunto das normas jurídicas, tanto em significado, quanto em extensão. A interpretação sistemática não sucede nem antecede o Direito: é contemporânea dele. Empresta-lhe vida e dinamicidade. O conteúdo jurídico, por força de sua natureza valorativa, transcende o mero e esparsamente positivado.

Nesta acepção hermenêutica é que esse estudo busca analisar a viabilidade da recuperação para as Sociedades em Comum sob a ótica da responsabilização dos sócios por dívidas das Sociedades em Comum.

Trata-se de análise que parte da premissa do direito de tratamento desigual entre sujeitos economicamente desiguais e que direitos devem ser acessíveis, inclusive, àqueles que estão à sua margem. A concessão ou homologação da recuperação para as Sociedades em Comum buscará garantir as mesmas oportunidades que já usufruem as sociedades regularmente constituídas e economicamente viáveis.

A discussão, neste estudo, ocorre em torno de um requisito objetivo: o de que a recuperação das Sociedades em Comum deferida desde que esse processo trouxesse benefícios para a coletividade e não somente para os sócios ou para a Sociedade em si.

As Sociedades em Comum têm forte potencial de gerar empregos, além de contribuir para as receitas tributárias e no fomento à concorrência. No entanto, constata-se que mesmo diante de todos os seus deveres jurídicos e das externalidades sociais positivas, ao passar por crise econômico-financeira, não tem apoio jurídico para superá-la.

Bobbio (2007, p. 94) afirma que a atuação do direito se dá por meio de "normas gerais e abstratas" que não se adaptam à todas as situações, tampouco aos casos complexos, razão pela qual ele cria "desigualdade entre iguais e igualdade entre desiguais". É o que se busca aqui, tratamento diferenciado para as Sociedades em Comum, permitindo a elas o registro, após o pedido de recuperação, visando efetivar o direito no caso concreto.

Caso esse tratamento diferenciado não venha a ser efetivado, não se realizada a justiça, posto que para as obrigações, o sistema jurídico equipara 
as Sociedades em Comum com as empresas regularizadas, todavia, no que tange às oportunidades de permanência no mercado, o mesmo não ocorre. Bobbio (2007, p. 94) critica esse engessamento do sistema jurídico "por mais que o juiz tenha a melhor intenção de fazer justiça, tal fim frequentemente se torna impossível pela própria estrutura das normas jurídicas".

Busca-se, por meio da interpretação sistêmica, apontar maior liberdade para que o juiz venha a deferir a recuperação judicial ou homologar a recuperação extrajudicial das Sociedades em Comum, a despeito da exigência legal, visando garantir a vivência com os valores da segurança e justiça. Neste sentido destaque-se a afirmação de Freitas (1995, p. 16) "o Direito legislado afigura-se como uma rede de coordenadas, na qual deve obrar o intérprete, perscrutando caminhos e desvendando riquezas, especialmente aquelas ocultas sob a superfície".

Vale frisar, que a ideia não é a recuperação de toda e qualquer Sociedade em Comum e, sim, somente daquelas que possuem condições econômicas para permanência no mercado, que já tenham um tempo mínimo de atuação empresarial (sugere-se dois anos) e cumpram sua função social.

O prazo de dois anos estabelecidos pela legislação concursal, ao ser considerado o período em que a sociedade esteja plenamente constituída perante os órgãos competentes, não encontra guarida no princípio basilar da Lei 11.101/2005, que é o da preservação da empresa viável economicamente.

Por essa razão, na análise do caso concreto e de forma restrita, há que se interpretar que os dois anos de atividade regular sendo um período mínimo em que a atividade deve ser exercida, de modo ininterrupto, e não dois anos do registro do contrato social perante a Junta Comercial.

Há também a seguinte questão a analisar: é possível interpretar a legislação em benefício das Sociedades em Comum sem que isso traga insegurança jurídica? Para isso, é necessário entender o que vem a ser a segurança jurídica nos moldes atuais e também tradicionalmente.

A segurança jurídica está relacionada com a estabilidade. Em um primeiro momento, fala-se em segurança do Direito, enquanto atualmente aborda-se a segurança por meio do Direito. Tal diferenciação se faz importante para entender que a concessão da recuperação judicial ou a homologação da recuperação extrajudicial para as Sociedades em Comum não acarreta insegurança aos ambientes econômico e jurídico. 
A segurança do Direito, nos dizeres de Silva (2004, p. 16-17) é compreendida sobre dois aspectos: i) segurança do direito e ii) segurança jurídica:

A segurança do direito é a que exige a positividade do direito e é, neste contexto, que a segurança se entronca com a Constituição, na medida em que esta constitui o fundamento de validade do direito positivo. [...] A segurança do direito, como visto, é um valor jurídico que exige a positividade do direito, enquanto a segurança jurídica é já uma garantia que decorre dessa positividade.

Para o autor, a segurança jurídica está relacionada com a sua positividade, ou seja, aquilo que o Direito estabelece, dessa forma, a segurança jurídica estaria atrelada apenas a aspectos formais. Todavia, a segurança jurídica abarca também um aspecto material que exige a satisfação de valores estabelecidos pela Constituição. Brito (2011, p. 6) afirma que "este é um reclame do Estado contemporâneo, que supera a mera exigência de observância da estrita legalidade, em prol da efetivação de valores atrelados à realização dos valores e princípios constitucionais".

Assim, não basta cumprir com as normas contidas nos textos do direito positivo. Caso a norma fira princípios deve-se privilegiar a posição hierárquica da principiologia que norteia o domínio econômico.

Diante da análise em foco, a legislação concursal estabelece que há necessidade de regular exercício da atividade empresária pelo período mínimo de dois anos para que seja possível a recuperação da empresa, portanto, para garantir a segurança jurídica formal este tempo deve ser respeitado. Porém, interpretar que o regular exercício da atividade empresarial se restringe ao registro não gera o desejável ambiente de segurança jurídica material. Esta engloba condutas testadas diante dos valores constitucionais, entre eles, além dos já referidos, o da eficiência da atividade empresária que deve ser analisado.

Alerte-se que as Sociedades em Comum recebem tratamento igualitário em relação às sociedades formalizadas quando diz respeito às obrigações na esfera tributária, consumerista, trabalhista e concorrencial. No entanto, o tratamento é desigual e injusto diante da possibilidade de recuperação judicial ou extrajudicial. Tem deveres jurídicos, mas, lhe é negado direito fundamental de permanência no mercado quando for economicamente viável.

Defende-se, finalmente, que o ato do registro seja interpretado ato jurídico declaratório e não constitutivo de direitos. Não haveria a sua dispensa, 
mas, deveria ser realizado em tempo determinado caso seja reconhecida a sua viabilidade econômica. Assim, cumpriria a exigência legal.

\section{CONSIDERAÇÕES FINAIS}

As Sociedades em Comum, atualmente, têm seu regime jurídico estabelecido no Código Civil, nos arts. 986 a 990. Essa regulamentação trouxe como principal característica a responsabilidade dos sócios pelas dívidas das Sociedades em Comum depois de esgotado o patrimônio especial separado para o desenvolvimento da atividade.

Não são sociedades irregulares quando têm objeto de exploração lícito, são apenas informais por não corresponderem com as formalidades estabelecidas em lei para a sua regularização perante a Junta Comercial.

A Lei de Concorrência prevê que a regularização perante o órgão competente não é condição necessária para sua responsabilização por ilícitos concorrenciais. No campo tributário, os entes considerados sem personoalidade jurídica podem ser sujeitos passivos na relação jurídico-tributária, isso porque na necessidade de execução fiscal, os sócios são responsáveis pelo pagamento, após esgotado o patrimônio social. O Código de Defesa do Consumidor também possibilita que as Sociedades em Comum sejam responsabilizadas como fornecedoras quando seus produtos trouxerem danos para os consumidores. E, por fim, a Consolidação das Leis do Trabalho (CLT) estabelece que na hipótese de não pagamento das verbas trabalhistas, o trabalhador pode intentar reclamatória trabalhista em face das Sociedades em Comum, tendo os seus sócios por responsáveis pelo pagamento.

Embora a legislação trabalhista, consumerista, tributária e concorrencial a considere sujeito de deveres jurídicos, a interpretação majoritária da Lei 11.101/2005 (artigos 48 e 161), advoga pela impossibilidade do direito a recuperação judicial pelas Sociedades em Comum.

Defende-se que tal entendimento não está conforme a interpretação sistemática, pois prestigia uma interpretação literal. Ou seja, é preciso recorrer aos valores e normas que compõem a ordem jurídica, em especial o subsistema jurídico-econômico, de modo a viabilizar a vivência com a segurança jurídica material.

Entre os argumentos que devem ser destacados para estender a recuperação judicial a esta forma societária estão: i) a igualdade material que justifica o tratamento desigual para situações desiguais, ou seja, ela não pode 
ser tratada tal qual são as demais empresas tendo em vista o princípio da inclusão econômica; ii) importância das externalidades positivas que a permanência desta sociedade na atividade econômica permite, entre elas, a geração de emprego, receitas tributárias, ambiente concorrencial; iii) a recuperação judicial seria possível somente para empresas que fossem economicamente viáveis, permitindo a efetividade do princípio da preservação da empresa; iv) a atuação efetiva mínima de dois anos, independentemente do registro comercial, uma vez que este pode ser interpretado de natureza declaratória.

É muito importante viabilizar a recuperação judicial para as Sociedades em Comum pois elas são responsáveis pela geração de inúmeros empregos, principalmente para pessoas excluídas do mercado formal de emprego, também pela geração de impostos e fomento da concorrência por possibilitar maior escolha aos consumidores. Ao realizar essas atividades, a Sociedade em Comum cumpre com os princípios e fundamentos da Ordem Econômica Brasileira previstos no art. 170 da CF, razão pela qual devem ter o seu direito a recuperação judicial respeitado quando passarem por problemas econômicofinanceiros, desde que optem por realizar o seu registro em momento oportuno designado pelo juízo concursal.

\section{REFERÊNCIAS}

AMARO, Luciano. Direito tributário brasileiro. 13. ed. São Paulo: Saraiva, 2007.

ANDRADE, Ronaldo Alves. Curso de direito do consumidor. Barueri: Manole, 2006.

BARTINI, Caio. Direito tributário. São Paulo: Revista dos Tribunais, 2012. (Coleção Elementos do Direito).

BOBBIO, Norberto. Da estrutura à função: novos estudos de teoria do direito. Tradução de Daniela Beccaccia Versiani. Barueri: Manole, 2007.

\section{BRASIL. Constituição da República Federativa do Brasil de 1988.}

Disponível em: < http://www.planalto.gov.br/ccivil_03/constituicao/ constituicaocompilado.htm>. Acesso em: 20 mar. 2013. 
. Lei $\mathrm{n}^{0}$ 5.172, de 25 de outubro de 1966. Dispõe sobre o Sistema Tributário Nacional e institui normas gerais de direito tributário aplicáveis à União, Estados e Municípios. Disponível em: $<$ http:// www.planalto.gov.br/ccivil_03/leis/15172.htm>.Acesso em: 29 jan. 2014.

. Lei $\mathbf{n}^{0} \mathbf{8 . 0 7 8}$, de 11 de setembro de 1990. Dispõe sobre a proteção do consumidor e dá outras providências. Disponível em: $<$ http:// www.planalto.gov.br/ccivil_03/leis/18078.htm>. Acesso em: 20 dez. 2013.

.Lei $\mathbf{n}^{\mathbf{0}} \mathbf{1 0 . 4 0 6}$, de 10 de janeiro de 2002. Institui o Código Civil. Disponível em: < http://www.planalto.gov.br/ccivil_03/leis/2002/ 110406.htm >. Acesso em: 20 mar. 2014.

. Lei $n^{0}$ 12.529, de 30 de novembro de 2011. Estrutura o Sistema Brasileiro de Defesa da Concorrência; dispõe sobre a prevenção e repressão às infrações contra a ordem econômica; altera a Lei no 8.137, de 27 de dezembro de 1990, o Decreto-Lei no 3.689, de 3 de outubro de 1941 [...]; e dá outras providências. Disponível em: <http://www.planalto.gov.br/ ccivil_03/_ato2011-2014/2011/Lei/L12529.htm>. Acesso em: 20 mar. 2014.

. Decreto-Lei $\mathbf{n}^{\mathbf{0} 5.452}$, de $1^{\circ}$ de maio de 1943. Aprova a Consolidação das Leis do Trabalho. Disponível em: $<$ http:// www.planalto.gov.br/ccivil_03/decreto-lei/del5452.htm>. Acesso em: 6 fev. 2014.

. Tribunal Regional Federal da $4^{\mathrm{a}}$ Região. Apelação/Reexame Necessário $n^{0}$ 2003.70.02.003303-8. Relator: Ministro Vilson Darós. Publicado no D.E. em 04 de novembro de 2008. Disponível em: $<$ http:// www2.trf4.gov.br/trf4/processos/visualizar_documento_gedpro.php?local $=$ trf4\&documento $=2518298 \&$ hash $=3124 \mathrm{bdffc} 31 \mathrm{c} 4749 \mathrm{bdc} 7 \mathrm{fdf0} 15 \mathrm{a} 87 \mathrm{f} 9 \mathrm{f}>$. Acesso em: 3 fev. 2014.

. Superior Tribunal de Justiça. Recurso Especial $\mathbf{n}^{0}$ 519.310/SP. Relatora: Ministra Nancy Andrighi. Julgado em 20 de abril de 2004. Disponível em: $<$ https://ww2.stj.jus.br/processo/jsp/revista/ abreDocumento.jsp?componente $=$ ITA\&sequencial $=468454 \&$ num_registro 
$=200300580885 \&$ data $=20040524 \&$ formato $=P D F>$.

Acesso em: 5 fev. 2014.

. Tribunal Regional do Trabalho da $5^{\text {a }}$ Região. R.O. $\mathbf{n}^{\mathbf{0}}$

36000650055050161. Relator: Cláudio Brandão. Julgado em 18 de abril de 2006. Disponível em: <http://trt-5.jusbrasil.com.br/jurisprudencia/ 7455224/recurso-ordinario-ro-360006520 055050161-ba-00360006520055050161/inteiro-teor-13098646>. Acesso em: 6 fev. 2014.

BRITO, Mirella Barros Conceição. Segurança jurídico-tributária e proteção da confiança do contribuinte no estado de direito. Direito Unifacs: Revista Eletrônica Mensal, Salvador, n. 131, 2011. Disponível em: $<$ http:// www.revistas.unifacs.br/ index.php/redu/article/view/1483/1164>. Acesso em: 21 out. 2014.

CARVALHO, Paulo de Barros. Curso de direito tributário. São Paulo: Saraiva, 2009.

CENTRO ADMINISTRATIVO DE DEFESA ECONÔMICA - CADE. Guia prático do CADE: a defesa da concorrência no Brasil. 3. ed. São Paulo: CIEE, 2007.

CONFEDERAÇÃO NACIONAL DOS DIRIGENTES LOGISTAS CNDL. Mercado informal no Brasil. 2013. Disponível em: $<$ http:// www.cdlbh.com.br/portal/2067/Enquetes_e_Pesquisas/ Mercado_Informal_no_Brasil $>$. Acesso em: 9 mar. 2015.

DUBUGRAS, Regina M. V. Consolidação das leis do trabalho Introdução. In: MACHADO, Antônio Cláudio da Costa. CLT interpretada: artigo por artigo, parágrafo por parágrafo. 2. ed. Barueri: Manole, 2009. p. 2.

\section{OLIVON, Beatriz. Quanto o Brasil produziu na informalidade em}

2012? Reportagem da revista Exame publicada em 10 de julho de 2013. Disponível em: http://exame.abril.com.br/economia/noticias/quanto-obrasil-produziu-na-informalida de-em-2012. Com acesso em 09 de março de 2015. 
FILOMENO, José Gerado Brito. Disposições gerais. In: GRINOVER, Ada Pellegrini et al. Código brasileiro de defesa do consumidor: comentado pelos autores do anteprojeto. 9. ed. Rio de Janeiro: Forense Universitária, 2007. p. 31-48.

FIUZZA, Ricardo. Novo código civil comentado. São Paulo: Saraiva, 2004.

FREITAS, Juarez. A interpretação sistemática do direito. São Paulo: Malheiros, 1995.

GONÇALVES NETO, Alfredo de Assis. Direito de empresa: comentários aos artigos 966 a 1.195 do Código Civil. 2. ed. São Paulo: Revista dos Tribunais, 2008.

INSTITUTO BRASILEIRO DE GEOGRAFIA E ESTATÍSTICA - IBGE. Síntese de Indicadores Sociais: Uma análise da condição de vida da população brasileira. Ano de Publicação: 2014. Disponível em: <tp:// ftp.ibge.gov.br/Indicadores_Sociais/Sintese_de_Indicadores_Sociais_2014/ SIS_2014.pdf. Com acesso em 09 de março de 2015.

LANZA NETO, Henrique. Sociedade em comum: regularidade e provas de sua constituição. In: CONGRESSO NACIONAL DO CONPEDI, 17. 2008, Brasília. Anais... Brasília, 2008. Disponível em: <http://

www.conpedi.org.br/manaus/arquivos/anais/brasilia/ 12_508.pdf $>$. Acesso em: 30 mar. 2014.

LEITE, Roberto Basilone. Introdução ao direito do consumidor: os direitos do consumidor e a aplicação do Código de Defesa do Consumidor. São Paulo: LTr, 2002.

LISBOA, Roberto Senise. Responsabilidade civil nas relações de consumo. São Paulo: Revista dos Tribunais, 2001.

MARTINS, Fran. Curso de direito comercial. 22. ed. Forense: Rio de Janeiro, 1998. 
NUNES, Luiz Antônio Rizzatto. Curso de direito do consumidor. 7. ed. São Paulo: Saraiva, 2012.

PAULSEN, Leandro. Curso de direito tributário completo. 4. ed. Porto Alegre: Livraria do Advogado, 2012.

SILVA, José Afonso. Constituição e segurança jurídica. In: ROCHA, Cármem Lúcia Antunes (Coord.). Constituição e segurança jurídica: direito adquirido, ato jurídico perfeito e coisa julgada. Belo Horizonte: Fórum, 2004.

Submetido em: 16/03/2015 Aprovado em: 12/05/2015

Como citar: KEMPFER, Marlene; COSTA, Juliana Hinterlang dos Santos. Interpretação sistêmica e a possibilidade de recuperação judicial para as sociedades em comum. Scientia Iuris, Londrina, v.19, n.1, p.125-148, jun.2015. 